\title{
Bir milletin kültürel belleğinin şifreleri: Kod kültürleri
}

\section{Hakan SARAÇı}

APA: Saraç, H. (2019). Bir milletin kültürel belleğinin şifreleri: Kod kültürleri. RumeliDE Dil ve Edebiyat Araştırmaları Dergisi, (Ö6), 157-169. DOI: 10.29000/rumelide.648467

\section{$\ddot{\mathbf{O} z}$}

İnsanoğlu doğayla olan mücadelesi sonrası maddi ve manevi kazanımlar elde etmektedir. Birlikte edinilen bu değerler her toplumun kendine özgü kültürünü oluşturmaktadır. Zamanla biriken bu veriler toplumların kültürel belleğinin oluşumuna zemin hazırlamaktadır. Dinamik, kolektif ve sistematik yapısı sayesinde kültürel bellekte geçmişten bugüne toplumların tüm kültürel verileri saklanmaktadır. Bu değerli verilerin sonraki kuşaklar arası aktarımı ise dilde gerçekleşmektedir. Bunun için dil toplumların kültür belleğinde bulunan evrensel, ulusal ve kültürel değerlerini dil göstergelerine kaydetmektedir. Neredeyse her toplumun dilinde bu verileri şifreleyen ve deşifre eden çeşitli kodlar bulunmaktadır. Bu kültürel bilgiler farklı toplumlarını ve onların kültürlerinin öğrenilmesi ve tanınması için anahtar görevi üstlenmektedirler. Bu evrensel ve ulusal değerlere kod kültürleri veyahut kültür kodları denilmektedir. 20. yüzyılın sonlarında araştırmacıların dilbilimde yapısalcı bakış açısı yerine antropolojik yaklaşımı benimsemesi dil ve kültür etkileşim sorunlarına yönelik çalışmaların başlamasını sağlamıştır. Böylece dilbilimde alt disiplinlerin doğuşu kaçınılmaz olmuştur. Bu bağlamda, dil ve kültür arasındaki etkileşim sorunlarının kültürdilbilimsel yaklaşım çerçevesinde incelenmesi yeni kuram ve kavramların ortaya çıkışını sağlamıştır. Bu çalışmada, dil ve kültür etkileşim sorunlarının çözümünde önemli bir rol üstlenen kültürdilbilimin oluşumu ve gelişimi incelenmektedir. Buna istinaden, toplumların dünya görüşü, mantalitesi, ulusal ve kültürel değerleri gösteren kod kültürlerinin tahlili yapılmaktadır. Bunun için çalışmada ileri sürülen görüş ve varsayımlar Rusça ve Türkçe örneklerle aydınlatılmaktadır. Sonuç bölümünde ise elde edilen sonuçlar değerlendirilmektedir.

Anahtar sözcükler: Dilbilim, kültürdilbilim, kod kültürler, dil dünya görüşü, ulusal ve kültürel değerler.

\section{Codes of a nation's cultural memory: Codes of culture}

\begin{abstract}
Human beings are gaining material and spiritual values after their struggle with nature. These values acquired together constitute the unique of each society. These data accumulated over time provide the basis for the formation of cultural memory of societies. Through its dynamic, collective and systematic structure, all cultural data of societies from past to the present are stored in cultural memory. The transfer of this valuable data among the next generations takes place in the language. For this reason, language records to linguistic signs the universal, national and cultural values of societies that appear in the cultural memory. In almost every community's language there are various codes that encrypt and decipher this data. This cultural knowledge plays a key role in the learning and recognition of different societies and their cultures. These universal and national values are called
\end{abstract}

1 Dr. Öğr. Üyesi, Anadolu Üniversitesi, Edebiyat Fakültesi, Rus Dili ve Edebiyatı Bölümü (Eskisehir, Türkiye), h_sarac@anadolu.edu.tr, ORCID ID: 0000-0003-0103-4029 [Makale kayit tarihi: 02.10.2019-kabul tarihi: 20.11.2019; DOI: $10.29000 /$ rumelide.648467] 
are called code cultures or culture codes. The fact that researchers adopted an anthropological approach rather than structuralism in linguistics by the end of the last century has led to the beginning of studies on the problems of language and culture interaction. Thus, rise of sub-disciplines in the linguistics was inevitable. In this context, the study of the interaction problems between language and culture with the framework of linguoculturogical approach has led to the emergency of new theories and concepts. In this study, the formation and development of linguoculturology, which plays an important role in solving the problems of language and culture interaction, is examined. Accordingly, code cultures showing the linguistics views of the world, mentality, national and cultural values of societies are analyzed here. The views and assumptions put forward in this study are illuminated with Russian and Turkish examples for this purpose. In conclusion, the results obtained are evaluated.

Keywords: Linguistics, linguoculturology, codes culture, linguistics views of the world, national and cultural values.

\section{Giriş}

Gizemli yapısından dolayı dil olgusu yüzyıllar boyunca araştırmacılar tarafından yorumlanmış, hakkında birçok defa tanım yapılmış ve birçok varsayım ortaya atılmıştır. Fakat, bilim dünyasında dil hakkında kesin bir yargıya varılamadığı gibi kesin bir tanımı da ortaya konulamamıştır. 19.yüzyılın sonu itibariyle dil olgusunun daha iyi anlaşılması ve yorumlanması için gücünü aldığı faktörlerin ele alınıp araştırılması gerektiğini düşünen araştırmacıların sayısı giderek artmıştır; W. Humboldt, K. Fossler, A.A. Potebnya, F. Boas, E. Sapir, B. Whorf, İ.A. Boduen de Courtaine, L. Weisgerber, F.İ. Buslayev, G.O. Vinogradov ve diğerleri. Bu bilim insanları kültürün, oluşum ve gelişim sürecinde dili sürekli besleyen, varlı̆̆ıyla onu diri tutan ve yapısını şekillendiren en önemli etken olduğunu sürekli olarak dile getirmişlerdir.

Dil ve kültür yapıları arasında meydana gelen etkileşim sorunlarına dikkat çeken Alman dil felsefecisi W. Humboldt'un "Dil, kültürün aynasıdır." tespiti dilbilim alanında yeni bir dönemin kapısını aralamıştır (Humboldt, 2000: 18). W. Humboldt'un bu önemli tespiti sonrası, dil ve kültür olgularının sıkı bir bağ içinde olduğunun anlaşılması, günümüz dilbiliminde ve çeşitli bilim dallarında bu konuya yönelik gittikçe büyüyen ilginin başlangıç noktası olmuştur. Günümüzde sosyal bilimlerde, dil ve kültür etkileşimi konusunda yeni kuramlar ortaya atılmakta ve bu kuramlar bilim dünyasında aktif bir şekilde tartışlmaktadır.

Dil ve kültür etkileşimi sorunlarının çözümünde etkili rol oynayan, birçok sosyal bilim dalını aynı çatı altında toplayarak onlara ortak çalışma ortamı sunan ve bu nedenle disiplinler arası alan olma özelliği taşıyan kültürdilbilimin temelleri W. Humboldt'un çalışmaları ile atılmıştır. W. Humboldt'un dil ve kültür etkileşimi ile ilgili görüşleri başta dilbilimciler olmak üzere farklı alan uzmanları tarafından da benimsenerek geliştirilmeye çalışılmıştır. 20.yy başında dilbilim ve budundilbilim alanlarında gerçekleştirmiş olduğu çalışmalarla adını duyuran Amerikalı araştırmacı E. Sapir, W. Humboldt'un görüşlerine dayanarak dil olgusunun, kültürün sosyalleşmiş yapısı ve anlamını taşıyan bir öğesi olduğunu öne sürmüştür (Sapir, 1993).

20. yüzyıl dilbiliminde dilin incelenmesi konusundaki yaklaşımların sürekli değişim göstermesi, dil ve kültür etkileşimi sorunlarının çözümünde istenilen sonuçların elde edilmesini geciktirmiştir. Fakat, 
geçtiğimiz yüzyılın sonundan itibaren dilbilimcilerin yapısalcı² bakış açısından uzaklaşarak antropolojik paradigma yaklaşımını benimsemesi dil ve kültür etkileşimi ile ilgili çalışmaların çeşitli yöntemlerle yeniden ele alınmasını sağlamıştır.

Dilbilimin gelişiminde işlevsel olan çeşitli disiplinlerin (bilişsel dilbilim, budundilbilim, ülkedilbilim, ruh dilbilim ve kültürdilbilim vb.) ortak çıkış noktası, dil ve kültür fenomenlerinin ayrılmaz yapılar olduklarını savunmalarıydı. Bu durum dilbilimini; tarih, etnografya, mitoloji, halkbilim ve psikoloji gibi çeşitli sosyal bilim dallarıyla daha da yakınlaştırarak ortak bir noktada buluşturmuştur. Dilbilimde antropolojik paradigmanın yerleşmesi ile birlikte dil olgusunun; kültür, bilinç, düşünce ve insan ile olan etkileşim sorunları farklı yaklaşımları çerçevesinde incelenmeye başlanmıştır.

\section{Kültürdilbilim}

W. Humbolt'un, A.A. Potebnya, E. Sapir, B. Worf, H.I. Tolstoy, A.A. Leont'yev gibi birçok araştırmacının çalışmalarında dil ve kültür olguları arasındaki etkileşim sorunlarıyla ilgili öne sürdükleri ilkeler kültürdilbilimin teorik olarak alt yapısını oluşturmaktadır. Dil ve kültür etkileşimi sorunları odaklı çalışmalar uzun süredir devam etmesine rağmen, geçtiğimiz yüzyılın son çeyreğinde kültürdilbilim sosyal bilimlerde bağımsız bir disiplin olarak kendini göstermiştir. Dilbilim, halkbilim, budundilbilim, mitoloji ve etnografi gibi sosyal bilim alanlarını ortak bir paydada buluşturmasından dolayı kültürdilbilim disiplinler arası bir alan olarak kabul edilmektedir. Rus dilbilimci V.A. Maslova, kültürdilbilimin çıkış noktasının yakın alanlar olan dilbilim, kültürbilim, ruhdilbilim ve etnografya olduğunu öne sürerken kültürdilbilimin araştırma alanının ise dil, insan ve kültür etkileşim sorunları olarak görmektedir (Maslova, 2001).

Bilim dünyasında kültürdilbilimin oluşumu ve gelişimi antropolojik paradigma yaklaşımı çerçevesinde Rus dilbilimi araştırmacıları tarafından dil-kültür-insan ve dil-kültür-bilinç üçlüleri arasındaki ilişkilerin incelenmesi sonucu gerçekleşmiştir. Rus dilbilimi ekolü katkılarıyla dünya dilbilimine kazandırılan kültürdilbilim kendi yöntemleriyle dil, kültür, insan ve bilinç fenomenlerinin etkileşim sorunlarına farklı bir bakış açısı getirerek dünya dilbiliminin uzun yıllar boyunca aradığı cevapların bulunmasını kolaylaştırmıştır. Dil hakkında yürütülen çalışmaların insan ve kültür merkezli olması gerekliliğinin yeniden gündeme taşınması kültürdilbilim disiplininin oluşumunu ve gelişimini hızlandırmıştır.

Kültürdilbilim alanı araştırmacıları, bir toplumunun kültürünün tanınması ve öğrenilmesinin dil öbeklerindeki (söz ve söz grupları) kültür olgularının ortaya çıkarılması ve tasvir edilmesiyle mümkün olabileceğini savunmaktadır. Çünkü; bir halkın geçmişi, gelenekleri, yaşam tarzı, düşünce ve kültür yapısı o halkın dilinin kapsamlı bir şekilde incelenmesi sonucu tanımlanmakta ve öğrenilmektedir. Bunun da ancak kültürdilbilimsel yaklaşım çerçevesinde kültür olgularının belirlenmesi ve betimlenmesiyle mümkün olabileceği görüşü kültürdilbilim araştırmacılarınca öngörülmektedir.

Fikirleriyle modern dilbiliminin kurucusu kabul edilen Ferdinand de Saussure, dilin artzamanlı (diachoronic) bakış açıSı yerine eşzamanlı (synchoronic) yaklaşım çerçevesinde incelenmesi gerektiğini öne sürmüştür. Araştırmacının bu düşüncesi 19. yüzyılın ikinci yarısında sosyal bilimlerde özelliklede dilbiliminde ortaya çıacak yeni bir yaklaşımın temellerini oluşturmuştur. "Saussure, Avrupa'da dili tarihsel bir nesne ve araştırma alanı olarak kabul edilen bir geleneği, dili tarihten bağımsız olarak incelenecek bir varlık olarak görmesiyle yıkmıştır. Saussure’ün başlattığı bu yeni bakış açısı yapısalcı dilbilim olarak adlandırılmaktadır" (Bircan, 2015: 46). Diğer bir deyişle, dilbilimindeki yapısalcı yaklașım dilin hem tarihsel süreç içerisindeki değişikliklerden hem de etkileşimde olduğu diğer olgulardan arındırılarak bağımsız, kendi kuralları içerisinde incelenmesi gerektiğini savunmaktadır. 
Ülkemiz dilbilim alanında son yıllarda yürütülen çalışmalar neticesinde kültürdilbilim kendisini yavaş yavaş göstermeye başlamıştır. Prof. Dr. Zeynep Bağlan Özer’in danışmanlığında, Gazi Üniversitesi Rus Dili ve Edebiyatı Bölümü doktora öğrencileri tarafından, Rus dilbiliminde kültürdilbilimi disipliniyle ilgili çeşitli dergilerde yayımlanmış makalelerin seçilip Türkçeye çevrilmesi sonucu oluşan makale derleme kitabı bu çalışmalardan bir tanesidir. Türkiye'de kültürdilbilimin tanınması ve gelişimi adına hazırlanan bu makale derleme kitabı 2014 yılında 'Kültürdilbilim Temel Kavramlar ve Sorunlar' adıyla çıkarılmıştır. Bu çalışma "dil ve kültür etkileşimi sorunları üzerine odaklanan kültürdilbilimin bağımsız bir bilimsel alan olarak tanıtılması, dil ve kültür sorunları ile ilgilenen bilişsel dilbilimin temel kavramlarının açıklanması, ülkedilbilim başta olmak üzere diğer bilimlerden farklılıklarının belirlenmesi, kültürdilbilim çerçevesinde kullanılan başlıca kavramların tanıtılması ve Türkçeye kazandırılması" amaçlarıyla yapılmıştır (Kozan, 2014: 4). Çalışmada "ileri sürülen terimlerin ve kavramların Türkçe karşılıkları öneri niteliği taşımakta ve tartışılmaya açıktır” vurgusu yapılmaktadır (a.g.e., s. 4). Bu terim ve kavramlardan bu çalışmada da yararlanılmıştır.

$\mathrm{Bu}$ çalışmada ülkemiz dilbiliminde son yıllarda varlı̆̆ını göstermeye başlayan kültürdilbilimin kavramlarından biri olan kod kültürlerinin tanıtılması ve ilgili terimlerin Türkçeye kazandırılması amaçlanmaktadır.

Kültürdilbilim alanın bağımsız bir disiplin olarak bilim dünyasında yer almaya başlaması ilk olarak Rus dilbilimi sınırları içerisinde olmuştur. Rus dilbilim ekolü araştırmacılarının kültürdilbilim çalışmalarında ortaya koymuş olduğu görüşler ve uygulanan yöntemler birbirinden farklılık göstermektedir. Bu yüzden, Rus dilbiliminde kültürdilbilim disiplini çerçevesinde incelenen dil ve kültür etkileşimi sorunları farklı bakış açılarıyla araştırımaya başlanmıştır. Böylece, kültürdilbilim alanının teorik olarak temellendirilmesi ve gelişimi adına yapılan çalışmalarda farklı ekoller ortaya çıkmıştır. Kültürdilbilim ekollerinin amaç ve yöntemlerinde farklılıklar bulunmasına rağmen, bazı ortak yaklaşımların olduğunu söyleyebiliriz:

Dil ve kültürün sürekli diyalog halinde olması;

Her iki olgunun birbirini tamamlayan ayrılmaz yapılar olduğu;

Dil ve kültür kişinin dünya görüşünü yansıtan, birbirine eşit iki bilinç yapısı olması;

Her iki fenomenin daimi nesnesinin birey/toplum ve kişilik/topluluk olması;

Dil ve kültür olgularının bireyi ve toplumu oluşturan normlar olması;

Her iki yapının tarihsel bir geçmişe sahip olması;

İletişimsel bir yapıya sahip olmaları;

Dil ve kültür olgularının iki ayrı gösterge sistemi olması (Stepanov, 2004; Teliya 1996; 2006a).

'Kültürdilbilimde Temel Kavram ve Sorunlar' makale derleme kitabında Rus dilbiliminde 4 ekolden bahsedilmektedir.

Anadili konuşurları açısından deyimlerin çözümlenmesi üzerine odaklanan V.N. Teliya'nın ekolü;

Farklı dönem metinlerinin aracılığıyla yapılan kültür değişmezlerinin betimlenmesini amaçlayan Yu.S. Stepanov'un ekolü;

Farklı dönemlerin ve milletlerin metinlerinin aracılığıyla kültür olgularını çözümleyen ve ‘Logiçeskiy Analız Yazıka' programı çerçevesinde gelişen N.D. Arutyunova'nın ekolü;

Karşılığı olmayan dil birimleri üzerinde duran V.V. Vorobyev'un ekolü (Kozan, 2014: 13). 
$\mathrm{Bu}$ çalışmanın amaç ve yöntemi Teliya ekolünde benimsenen kültürdilbilimsel yaklaşım çerçevesinde belirlenmiştir. Çalışmada Teliya'nın ekolünün belirlemiş olduğu yaklaşım temelinde, kültürdilbilimin kavramlarından olan 'kod kültürleri' incelenmektedir.

V.N. Teliya ve bu ekolün araştırmacıları, kültürdilbimsel yaklaşım çerçevesinde kültür olgularının dil işaretlerinde nasıl somutlaştığı ve ne şekilde yansıdığı, sonrasında bu kültürel bilgilerin dil öbeklerinde kaydedilme ve korunma süreçleri deyimler üzerinde uygulanan kültürdilbilimsel çözümleme yöntemiyle ortaya konulmaktadır. Teliya göre deyimler, "dil birimlerindeki en açık kültür katmanlarıdı»" (Teliya, 2006b: 782). Bu yüzden, Teliya ekolü çerçevesinde yürütülen kültürdilbilimsel araştırmalarda kullanılan dil materyallerinin büyük kısmını deyimler oluşturmaktadır.

$\mathrm{Bu}$ ekol kapsamında uzun yıllar süren araştırmalar sonrası, Teliya öncülüğünde bu akımın araştırmacıları tarafından 2006 yılında 'Büyük Rus Dili Deyimler Sözlügüu. Anlam. Kullanım. Kültürel Yorum'3 başlığı adında deyimler sözlüğü hazırlanmış ve yayımlanmıştır. Bu sözlüğün hazırlanışı “deyimlerin kültürdilbilimsel bakış acısıyla yorumlanmasını sağlayan araç-gereçlerin vasıtasıyla, dil öbeklerinde somutlaşmış, yansımış ve kaydedilmiş kültürel manaların çıkarımı ve tasviri” amacıyla gerçekleşmiştir (Teliya, 2006b: 778). V.N. Teliya ekolünün kültürdilbilimsel yaklaşım çerçevesinde oluşturmuş olduğu kültürdilbilim sözlüğü bu alanın en kapsamlı kaynaklarından biri olarak kabul edilmektedir. Bu sözlüğün hazırlanışı esnasında kültür olgularının en açık ve en yoğun şekilde kendisini gösterdiği dil materyalleri (özellikle deyimler, atasözleri, özlü sözler vb.) seçilerek, bu ekolün uzmanlarınca semantik, dilbilimsel, budundillimsel ve özellikle kültürdilbilimsel bakış açılarıyla ele alınıp tahlilleri yapılmıştır. Analizi gerçekleştirilen her söz öbeğinin ilgili dildeki güncel kullanımı çeşitli kaynaklardan derlenen örneklerle ortaya konulmaya çalışılmıştır.

Kültürdilbilim alanı içerisinde tasarlanan, hazırlanan ve yayınlanan diğer sözlükler şunlardır:

B.B. Krasnıh, I.V. Zakharenko ve D.B. Gudkov tarafından hazırlanan 'Rus Kültür Alanı Kültürdilbilimsel Sözlük'4 isimli çalışma kolektif bir çalışma sonrası 2004 yılında yayımlanmıştır. Bu değerli sözlükte Rus dilinde bulunan anıştırma5 isimler, anıştırma sözler ve anıştırma metinler incelenerek dilbilimsel ve kültürdilbilimsel çözümlenmesi yapılmıştır. Ayrıca, bu sözlükte kültürdilbilimsel yaklaşım çerçevesinde Rus halkının bilincinde oluşan çeşitli kültürel verileri betimleyerek Rus dil dünya görüşünün şemasını çizmeye çalışmışlardır. Bu sözlük M.V. Lomosov Moskova Devlet Üniversitesi Filoloji Fakültesi İletişim ve Söylem Teorisi Bölümü’nde yapılan çalışmalar sonucunda ortaya çıkmıştır.

Yu.S. Stepanov tarafindan hazırlanan ‘Değişmezler. Rus Kültürü Sözlüğü’’ adlı çalıșma 1997 yılında yayımlanmıştır. Bu sözlükte seçilen kavramlar kültürdilbilimsel yaklaşım çerçevesinde incelenerek, Rus kültürü alanının7 sınırları çizilmeye çalışılmıştır. Bu sözlük Rusya Bilim Akademisi Dilbilim Enstitüsü’nde gerçekleştirilen çalışmalar sonucunda ortaya çıkmıştır.

V.N. Teliya, 1996 yılında yayımlamış olduğu 'Semantik, Pragmatik ve Kültürdilbilimsel Yaklaşımında Rus Deyimbilimi’ adlı çalışmasında kültürdilbilim alanın konusu, nesnesi ve kuramları detaylı bir

Rus.: 'Bol'şoy Frazeologiçeskiy Slovar' Russkogo Yazıka. Znaçeniye. Upotrebleniye. Kul'turologiçeskiy kommentarii'. Rus.: 'Russkoye Kulturnoye Prostranstvo. Lingvokul'turologiceskiy Slovar'.

(Söz sanatı terimi) Bir şeyi, bir olayı, hatıra getirecek bir sözü bilerek söyleme (TDK). Yukarı bahsedilen anıştırma isimler, anıştırma sözler ve anıştırma metinlerden kastedilen, bir toplumun fertlerince tanınan ve bilinen isim, söz ve metinlerin uzun yıllar boyunca dilde varlığını sürdürerek kişinin belleğinde kültür olgusu haline dönüşmesi olayıdır.

Anıştırma isim: 'Mustafa Kemal Atatürk',

Anıştırma söz: Mustafa Kemal ve arkadaşlarının faaliyetlerini özetleyen 'Nutuk',

Anıştırma metin: Mustafa Kemal'in milli mücadele için bulunduğu Sivas kongresinde katılımcılara söylemiş olduğu 'Ya istiklal, ya ölüm' sözlerini verebiliriz.

$6 \quad$ Rus.: 'Konstantı. Slovar Russkoy Kul'turı'.

Kültür alanı: 'o kültür içinde yaşayanların bireysel ve toplumsal bilişsel alanlarıyla bağlantılı, bilincinde kültürün var olma biçimidir' (Kozan, 2014: 38). Örnek: Rus kültür alanı, Türk kültür alanı, Alman kültür alanı vs. 
şekilde ortaya koymuştur. V.N. Teliya'ya göre, kültürdilbilim "çağdaş (canlı) ulusal dilde yansıyan ve dilsel faaliyetlerde ortaya çıkan maddi kültürü ve halkın mantalitesini araştıran” bir bilim dalıdır (Teliya, 1996: 216). Araştırmacı bu çalışmasında söz konusu bilimsel alanın eşzamanlı olarak sürekli etkileşim içerisinde olduğu, aralarında yakın bir ilişki bulunan dil ve kültür etkileşimi sorunlarını inceleyen diğer bir bilim dalı olan budundilbilimin parçası olduğunu belirtmiştir. Fakat, V.N. Teliya okulunun uzmanlarına esin kaynă̆ı olan bu yapıtın yayımlanışından sonraki süreçte çok önemli ve ciddi çalışmaların ortaya konulması; kültürdilbilimin bağımsız bir disiplin olarak tanınmasını sağlamıştır. Bu süreç içerisinde kültürdilbilimsel yaklaşım çerçevesinde düzenlenen konferans, kongre, seminer, toplantı ve diğer bilimsel faaliyetler sosyal bilimlerde ve dilbiliminde kültürdilbilimin tanımasını ve gelişmesini sağlayacak sözlük, kitap, makale derleme kitabı ve çeşitli akademik çalışmaların ortaya çıkışına zemin hazırlamıştır.

V.N. Teliya’nın görüşlerine dayanarak, V.V. Krasnıh, kültürdilbilimini "dilde ve söylemde kültürün ortaya çıkışını, yansımasını ve kaydedilmesini inceleyen” bir bilim dalı olarak tanımlamaktadır (Krasnıh, 2002: 12). M.L. Kovşova'ya göre kültürdilbilim "dil, kültür ve milli mantalitenin arasındaki süreçleri incelemektedir" ve asıl amacının ise "deyimlerde yansıyan kültür olgularının kültürdilbilimsel çözümleme yöntemiyle dil öbeklerinde belirlenip betimlenmesi” olarak belirtmektedir (Kovşova, 2012: 56-57).

Sonuç olarak, kültürdilbilim, kültürdilbilimsel çözümleme yöntemiyle milli dil ve kültür etkileşimi sorunlarının derin ve titiz bir şekilde incelenmesine imkan sunan disiplinlerarası bir bilim dalı olduğu düşünülmektedir. Bugün de kültürdilbilim gelişimini sürdürmektedir. Bu çalışmada, kültürdilbilimsel yaklaşım çerçevesinde sunulan 'kod kültürleri' terimi incelenmekte olup çeşitli görüşler paylaşılmakta ve bu görüşlerin aydınlatılması adına birtakım örneklere yer verilmektedir.

\section{Kod Kültürleri}

Kültürdilbilimsel yaklaşım çerçevesinde dil ve kültürün sürekli etkileşim içerisinde olduğunu gösteren, dil ve kültür arasındaki etkileşim sorunlarının çözümüne odaklanan konulardan bir tanesi de 'kod kültürleri'dir. Bu yüzden, dilbilim uzmanları kültürdilbilimin amaç ve yöntemlerine uygun olarak kod kültürlerini belirleyerek onların dilbilimsel, budunbilimsel ve kültürdilbilimsel yaklaşım çerçevesinde analizlerini yapmaktadırlar. İki ayrı gösterge sistemi olarak kabul edilen dil ve kültür işaretlerinde bir toplumun milli (maddi ve manevi) kültürü, ulusal mantalitesi ve dil dünya görüşünün yansıması ve kaydedilmesi kültür kodlarının ${ }^{8}$ varlığının saptanması ile ortaya konulabilmektedir. Çünkü, bir kültür toplumunun evrensel ve ulusal-kültürel değerleri o toplumun diline yansımakta, kaydedilmekte ve kodlanmaktadır. Bu yüzden, kod kültürleri bir milletin ulusal-kültürel değerlerini kişinin belleğinde şifrelemekte ve aynı zamanda kişiye onları deşifre etme imkanı sunmaktadır (Gudkov ve Kovşova, 2007).

Kod kültürleri, Rus dilbilim ekolünde özellikle kültürdilbilim ve budundilbilim alan uzmanlarınca sıkça işlenmekte ve gelişimini günümüz sosyal bilim dalları sınırları içerisinde devam ettirilmektedir (bkz. H.I. Tolstogo, S.M. Tolstoy, Ye. Bart'minskogo, V.N. Teliya, M.L. Kovşova, V.V. Krasnıh, D.B. Gudkov, S.Ne. Nikitinoy, Ye.A. Berezoviça, I.V. Zykovoy, I.V. Zakharenko). Günümüzde kod kültürleri kavramı

\footnotetext{
8 Bu çalışmada bizler, kültürdilbilim bakıș açısıyla «Kültür kodu» ve «Kod kültürü» terimleri arasında anlamsal olarak herhangi bir farkın bulunmadığı ortaya koymakta ve her iki ifadenin de birbirinin yerine kullanılabildiğini önceden belirtmenin faydalı olacağını düşünmekteyiz.
} 
ile ilgili yapılan yorum, görüş ve tanımların V.N. Teliya'nın $(1996,2006)$ ortaya koymuş olduğu fikirler çerçevesinde geliştirildiği söylenebilir.

V.N. Teliya kod kültürlerini "kendi öz anlamına ek olarak, bünyesinde çeşitli kültür olgularını bulunduran tüm söz ve söz grupları” olarak tanımlamaktadır (Teliya, 1996: 216). D.B. Gudkov kod kültürlerini "insanoğlunun çevresinde bulunan (doğal ya da yapay) herhangi bir nesnenin temel (ilk) anlam fonksiyonunu yerine getirmesi dışında, birtakım ek (ikincil) anlamları da taşıyabilme özelliği gösteren ad ve ad takımları" olarak yorumlamaktadır (Gudkov, 2004: 39). V.V. Krasnıh kod kültürlerini, "kültürün, insanın çevresinde bulunanları böldüğü, sınıflandırdığı, yapılandırdığı ve değerini belirlediği bir çeşit görünmez 'ă̆ olarak” tanımlamaktadır. (Krasnıh, 2002: 232). "Kod kültürleri kişinin geçmişten gelen en eski düşünce sistemidir. Kod kültürleri bu düşünceleri kodlamaktadır” (a.g.e., s. 232). M.L. Kovşova, "dünyanın - doğanın, yapay nesnelerin, insanın iç ve dış özelliklerinin - fiziksel yapılarından uzaklaşarak, insan bilincinde birtakım kültürel anlamlara büründüğünü’ savunmaktadır. Ayrıca, araştırmacı 'dil ve kültür işaretlerinde kendisini gösteren bu anlamların insan bilincinde bilgi, düşünce ve algı şeklinde ortaya çıktığını” söylemektedir (Kovşova, 2012: 174-175).

Kod kültürleri ile alakalı Rusça ve Türkçe örneklerden bazıları şu şekildedir:

1. 'Derya' sözcüğü Büyük Türkçe Sözlüğünde belirtilen ilk (asıl) anlamı "büyük su kütlesidir” (Doğan, 2011: 367). Fakat, ‘derya’ sözcüğü kendi öz anlamından uzaklaşarak, Türk halkının bilincinde birtakım sembolik ya da imgesel anlamlara bürünebilmektedir. Doğanın bir parçası olan 'derya' kavramının fiziksel olarak olağanüstü genişlikte ve derin bir yapıya sahip olması, 'derya' sözcüğünün kişinin bilincinde bu özelliklerinin yeniden yorumlanması sonucu kültürel bir anlama geldiği görülmektedir. Böylece, ilk (asıl) anlamından uzaklaşan 'derya' sözcüğü Türkçede 'bilgeliği' simgelediği düşünülmektedir (bkz. derya gibi - çok bilgili kişi). ‘Derya' sözcüğünün Türkçede bu anlamda kullanıldığı örneklere metin içinde göz atalım:

Defile öncesi, üzerinde o kıyafetle röportaj yaptım. Derya gibi bir adam İslimiyeli Hoca. Bayıldım. Bu arada Işık Üniversitesi Güzel Sanatlar Fakültesi ilk mezunlarını veriyordu. Birkaç gün boyunca inanılmaz etkinliklere imza attılar. Gençlerin heyecanını, onları, destekleyen üniversite yöneticilerine ve öğretmenlerine şapka çıkardım.

Ahilik Haftası kutlamaları Denizli'de etkinliklerle sürdürülürken, Ahilik’in tüm yönleriyle araştırmasını yapan ve kitabını yazan, engin tecrübesi ve derya gibi bilgisiyle Ahilik geleneğine ışık tutan PAU Fen Edebiyatı Fakültesi Türk Dili Edebiyatı Bölümü Öğretim üyesi Doç. Dr. Turgut Tok, Ahilik örgütlenmesini hem tarihte hem de günümüzde, önemli izlerinin bulunduğu bölgelerden birinin Denizli yöresi olduğunu söylüyor.

Örneklerde görüldüğü gibi, Türk dilinde 'derya' sözcüğünün bürünmüş olduğu bu kültürel anlam Türk haklının düşünce sisteminin bir ürünü olup ulusal ve kültürel olgu olma özelliği taşımaktadır. Böylece, 'derya' sözcüğü taşımış olduğu bu sembolik anlam sayesinde Türk dilinin doğa kod kültürlerị kapsamına dahil edilmektedir.

2. 'Orman' ('Les') sözcüğü Rus dilinde akla ilk gelen anlamı "büyük bir geniş alanda yoğun bir şekilde büyüyen ağaçlar sürüsüdür”o (Ozhegov, Shvedova, 2006: 323). Fakat, Rus halkının bilincinde 'Orman' ('Les') kelimesi asıl anlamından soyutlanarak sahip olduğu özelliklerinin yeniden yorumlanması sonucu sembolik bir anlama dönüşmektedir. Rusçada benzetme amacıyla 'Orman' ('Les') sözcüğünün 'oldukça çok, aşırı sayıda' gibi anlamları da barındırdığı görülmektedir. Böylece, içerisinde kültürel bir anlam barındırması neticesinde 'Orman' ('Les') sözcüğünün Rus dili doğa kod kültürlerinden biri olduğu düşünülmektedir. Çünkü, 'Orman' ('Les') sözcüğünün bünyesinde oluşan bu sembolik anlamın sadece Rus halk mantalitesinin bir ürünü olduğu farklı dil ve kültürlere sahip toplumların dillerinde böyle bir kullanım görülmediği düşünülmektedir (bkz. 'orman kadar el'11,

Kod kültürlerinin sınıflandırılmasına aşağıdaki kısımda değinilmektedir. Rus.: 'Mnojestvo derev'yev, rastuşçik na bol'şom s somknutymi kronami'. Rus.: 'Les ruk'. 
'orman kadar ağaç'12 - çok sayıda elin ve ağacın olduğu anlamında söylenmektedir). Orman sözcüğünün Rus dilinde bu kültürel anlamındaki kullanımına ilişkin örnekler şu şekildedir:

А вот Женя искренне признался, что боится шприцев. Я, например, тоже боюсь. А ну-ка, проявите смелость, поднимите руки все те, кто боится шприцев! В зале засмеялись и поднялся лес рук. Только рука Цупы не поднялась, но я знал, что во время прививки оспы за билет на матч «Динамо» - ЦСКА он подсунул вместо себя другого мальчишку под иглу медсестры. - Нет тот трус, кто высказывает сомнения в себе, а тот трус, кто их прячет. Смелость - это искренность, когда открыто говоришь и о чужих недостатках, и о своих... [Евгений Евтушенко «Волчий паспорт» 1999]. (Çevr.: İşte, Zhenya şırıngadan korktuğunu açıça itiraf etti. Örneğin, ben de korkuyorum. Bu arada, cesaretinizi gösterin ve şırıngadan korkanlar ellerini kaldırsın! Salonda buna güldüler ve çok sayıda el kalktı. Yalnızca Tsupy elini kaldırmadı, ama Dinamo ve CSK maçı bileti için çiçek aşısı sırasında, Tsupy'nun başka bir çocuğun yerine hemşirenin iğnesinin altına yattı̆̆ını biliyordum. Korkak, kendisinden şüphe duyan ve bu şüpheyi saklayan kişidir. Cesaret, hem kendi hem de başkalarının eksiklikleri hakkında açıkça konuşulan samimi davranıştır).

Раньше, когда жил в полковой слободе, деревьев рядом, почитай, не было вовсе. Одни дома и заборы. После их - снова, а там - опять заборы. А здесь - лес деревьев под боком! И меж домов простор немалый. Дома в граде Петровом были разные. Были грамотные и превосходные (Борис Евсеев. Евстигней // «Октябрь, 2010). (Çevr.: Önceden Alay mahallesinde yaşadığımda, neredeyse etrafta hiç ağaç yoktu. Tek tip evler ve çitler. Onlardan sonra yine ve yeniden çitler. Burada yanı başımızda bir sürü ağaç. Evler arasında büyük bir alan. Grade Petrovo'da evler daha farklıydı. Onlar kocaman ve mükemmeldiler).

Kod kültürlerinin ne şekilde tasnif edildiğine değinecek olursak, V.N. Teliya’nın çalışmasında kod kültürlerini şu şekilde sınıflandırıldığı söylenebilir:

\begin{tabular}{|c|}
\hline İnsan (antromorf) kültür kodlari ${ }^{13}$ \\
\hline Hayvan (zoomorf) kültür kodları ${ }^{14}$ \\
\hline Bitki kültür kodları ${ }^{15}$ \\
\hline Doğa kültür kodları ${ }^{16}$ \\
\hline Ev-Eşya kültür kodları17 \\
\hline Giyim-Eşya kültür kodları ${ }^{18}$ \\
\hline Gıda (yiyecek/içecek) kültür kodları19 \\
\hline Yapı (mimari) kültür kodları ${ }^{20}$ \\
\hline Manevi kültür kodları ${ }^{21}$ \\
\hline Dini kültür kodları ${ }^{22}$ \\
\hline Zaman kültür kodları²3 \\
\hline Uzam kültür kodları ${ }^{24}$ \\
\hline Renk kültür kodları ${ }^{25}$ \\
\hline Beden kültür kodları ${ }^{26}$ \\
\hline
\end{tabular}

Beden kültür kodları²6

\author{
Rus.: 'Les derev'yev'. \\ Rus.: 'Antropniy ili Çeloveçeskiy kod kul'turı'. \\ Rus.: 'Zoomorfniy Kod Kul'turı' \\ Rus.: 'Rastitel'niy Kod Kul'tur'’ \\ Rus.: 'Prirodniy Kod Kul'tur'’ \\ Rus.: 'Artefaktivno-Veşniy Kod Kul'turı' \\ Rus.: 'Veşno-Kostyumniy Kod Kul'turı' \\ Rus.: 'Gastronomiçeskiy Kod Kul'turı' \\ Rus.: 'Arhitekturniy Kod Kul'turı' \\ Rus.: 'Duhovniy Kod Kul'turı' \\ Rus.: 'Religiozniy Kod Kul'turı' \\ Rus.: 'Vremennoy ili Temporal'niy Kod Kul'turı' \\ Rus.: 'Prostranstvenniy Kod Kul'turı' \\ Rus.: 'Tsevetovoy Kod Kul'turı' \\ Rus.: 'Telesniy ili Somatiçeskiy Kod Kul'turı'
}


Rakam kültür kodlari²7 (Teliya, 2006a).

V.N. Teliya, genel olarak kod kültürlerinin sınıflandırılma sayısının 4o'tan fazla olduğu ve başka kod kültürlerinin bu sınıflandırmaya dahil edilebileceğinden bu listeyi tartışmaya ve öneriye açık tutmuştur.

V.V. Krasnıh ise kod kültürlerini şu şekilde sınıflandırmıştır:

Beden kod kültürleri

Uzam kod kültürleri

Zaman kod kültürleri

Nesne kod kültürleri ${ }^{28}$

Canlı kod kültürleri²9

Manevi kod kültürleri

V.V. Krasnıh kod kültürlerini, "bir toplumun dil dünya görüşündeki en 'naif' halk fikirlerinin içinde kaydedildiği antik düşüncelerle ilişkilendirmektedir” (Krasnıh, 2003: 298). Ona göre, dünyanın (gerçeğin) tanınması ve betimlenmesi için 3 temel nesne bulunmaktadır: 1) Kişinin kendisi; 2) Dünyayı boydan boya çevreleyen uzam; 3) Zaman kavramı (a.g.e., s. 298).

V.N. Teliya'nın görüşüne dayanarak, M.L. Kovşova kültürdilbilim araştırmaları için kod kültürlerinin konusuna göre ayrılması gerektiğini savunmaktadır. Araştırmacıya göre kod kültürleri şu şekilde sinıflandırılmalıdır:

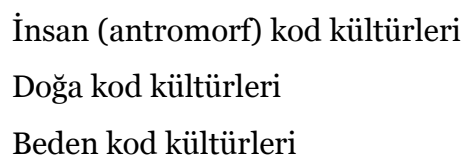

Kod kültürlerinin sınıflandırması ile alakalı farklı görüşler bulunmasına rağmen, kültürdilbilimsel yaklaşım çerçevesinde V.N. Teliya'nın görüşleri diğer araştırmacılar tarafından örnek alınmaktadır.

V.N. Teliya'nın sınıflandırmasına göre:

İnsan (antromorf) kod kültürleri: Kastedilmek istenen kişi ile ilgili ad veya ad takımlarının tümü: Anne, baba, kardeş, teyze, dayı, amca, kuzen, erkek, kadın, çocuk, yaşlı, genç, yakışıklı, hüzünlü, sevimli, ana baba bir, dünya ahret kardeşim (bacım) olsun, gençliğin kıymeti ihtiyarlıkta bilinir, adam içine karışmak vb.;

Beden kod kültürleri: Göz, kaş, kulak, burun, baş, ayak, parmak, göğüs, kol, gözden gönülden çlkarmak, gözünün üstünde kaşın var dememek, ağzı kulaklarına varmak, bir işe burnunu sokmak, alına yazılan başa gelir, alın teri dökmek vb.;

Rus.: 'Kolicestvenniy Kod Kul'turı'

Rus.: 'Predmetniy Kod Kul'turı'

Rus.: 'Biomorfniy Kod Kul'turı' 
Doğa kod kültürleri: Orman, dağ, deniz, göl, okyanus, uçurum, nehir, bataklık, hava, su, ateş, toprak, orman taşlamak, orman kibarı, çam devirmek, dağlara taşlara, taş taş üstünde bırakmamak, uçuruma sürüklenmek, dört yanı deniz kesilmek, damlaya damlaya göl olur, batağa saplanmak vb.

Renk kod kültürleri: Sarı, kırmızı, beyaz, mavi, pembe, yeşil, kahverengi, siyah, beyaz, mor, alnının kara yazısı, beyaz sayfa açmak, para peşin kırmızı meşin, mavi boncuk dağıtmak, yeşil ışık yakmak, alı alına, moru moruna vb.;

Gıda kod kültürleri: Ekmek, yă̆, tuz, şeker, süt, yoğurt, zeytin, bal, yoğurt, un, ekmek elden, su gölden, bir eli yağda, bir eli balda olmak, ananın ak sütü gibi (helal olsun), emdiği sütü burnundan getirmek, her yiğidin bir yoğurt yiyişi vardır, zeytin dalı uzatmak, arpa unundan kadayıf olmak, ağzından bal damlamak, bir şeyde tuzu olmak, erken kalktım işime, şeker kattım aşıma vb.;

Kozmik kod kültürleri: Gök, yer, hava, güneş, yıldız, ay, samanyolu, dolunay, gökte ararken yerde bulmak, güneş balçıkla sıvanmaz, yıldızı parlamak, ay parçası/ay gibi, yıldızı sönmek, gökten zembille inmek vb.

V.N. Teliya doğal dilin; vazgeçilmez araçları olan söz, deyimler, özlü sözler ya da herhangi bir metnin içerik ve yapı bütünlüğü içerisinde kültür 'dili’ göstergesi rolüne büründüğünün altını çizmektedir. Araştırmacı, bu roldeki en büyük payın dil birimlerdeki en doyumlu ve en derin kültürel manalara sahip olan deyimlere ait olduğunu vurgulamaktadır (Teliya, 2006b). Bu yüzden, Teliya ekolünce kod kültürlerin çıkarımını ve betimlenmesini çoğunlukla deyimler üzerinde gerçekleştirilmektedir.

Örneklerde yer verilen söz ve söz grupların her biri, kişinin bilincinde yeniden yorumlanması sonucu fiziki özelliklerinden soyutlanarak birtakım sembolik ya da imgesel anlamlara dönüştüğü görülmektedir. Bu nedenle, bu söz ve söz gruplarıyla ilgili bireylerin belleğinde oluşan bu mecaz anlamların dil ve kültür göstergelerinde yansıması sonucu ortaya çeşitli kültürel ya da sembolik anlamlar çıkmaktadır. Böylece, bu söz ve söz gruplarında yansıyan, kaydedilen ve kendini gösteren bu algı, düşünce ve bilgiler kültürel ya da sembolik anlamlara dönüşebilmektedir. Buna bağlı olarak arketipler, mitler, semboller, stereotipiler, inançlar, basmakalıp halk düşünceleri, gelenek-görenekler, ritüeller gibi değerleri; dil işaretlerinde yansıtan, kaydeden, kodlayan ve onlara simgesel anlamlar kazandırarak birer kültür olgusu olma özelliği kazandıran tüm söz ve söz gruplarına 'kod kültürleri' denilmektedir. Kod kültürleri eğretileme (istiare) söz sanatı yardımıyla bir nesnenin benzetme yoluyla başka bir nesnenin yerine kullanılması sonucu oluşmakta ve dilde ifade edilmektedir. Bu sayede, kod kültürleri kendi anlamının dışında birtakım mecazi (sembolik ve kültürleri) anlamlar içermektedirler.

Kod kültürleriyle ilgili diğer örnekler şu şekildedir:

Hayvanlar alemi hem Rus hem de Türk mitolojinde kullanılan en yaygın kültlerden biridir. Örneğin, 'kurt' sözcüğü. Bu sözcüğün gündelik hayatta kullanılan genel, akla ilk gelen anlamı hem Rusça hem de Türkçede aynı şekildedir. Fakat, 'kurt' imgesi Rus ve Türk halkının dünya görüşünde farklı çağrışımlar uyandırdığı görülmektedir. Ruslarda 'kurt', 'vahşi, acımasız, aç, yalnız, aşırı tehlikeli' gibi olumsuz çağrışımlar uyandırırken Türklerde ise tam aksine 'kurt', 'güçlü, sevimli, cesur, şefkatli, iyilik sever' gibi pozitif çağrışımlar uyandırmaktadır. 'Kurt' sözcüğü genel olarak Rusların dünya görüşünde 'tehlikeyi, yalnızlı̆̆ı, acımasızlığı ve vahşiliği’ simgelerken, Türklerde ise 'cesareti, yiğitliği, gücü’ sembolize etmektedir. 
'Kurt' sözcüğünün gündelik hayatta kullanılan akla ilk gelen anlamından soyutlanarak her iki ulusun bilincinde farklı şekilde algılandığı söylenebilir. Böylece, 'kurt' sözcüğü ile ilgili her iki toplumun bilincinde oluşan algıların farklılık göstermesi Rus ve Türklerin dil dünya görüşünde ve mantalitesinde bazı kültürel farkların olduğunu göstermektedir. Bu sosyo-kültürel açıdan oluşan farklılıklar toplumların yaşam tarzını, gündelik hayatını derinden etkilemekte ve şekillendirmektedir. Örneğin, Türkiye'de bir siyasi partinin de simgesi olan 'kurt' figürü Türkün savaş ruhunu, yaşam gücünü, özgürlüğünü ve cesaretini simgelemektedir. Cumhuriyetin ilk ylllarında basılan paraların üzerinde 'kurt' simgesinin olması 'kurt' motifinin Türk kültürün önemli bir değeri olduğunu göstermektedir.

Türkçede 'işini bilen, girişken kimse' anlamında kullanılan 'kurt gibi' deyimi Türk halkının bilincinde 'kurt' motifiyle alakalı oluşmuş olan olumlu çağrışımların dile olan yansımasını açık bir şekilde ortaya koymaktadır. 'Kurt’ sözcüğünün bu kültürel anlamıyla kullanımına ilişkin örnekler şu şekildedir:

G3 Forum’un bu yılki sloganının 'Yırtıcı Fikirler' olduğunu aktaran Yılmaz, "Katılımcılara 'kaplan gibi cesur musun, kurt gibi cin fikirli misin, şahin gibi ileri görüşlü müsün, baykuş gibi bilge misin?' diye soracağız. Katılımcılarımız da, yuvarlak masalarda mentorlarımıza hukuktan yatırıma kadar soru sorma imkanı bulacak" diye sordu; Bazen işimizde tam donanımlı olmamamız bizleri endişeye, şüpheye ya çıkmaza sokabilir. Tabii ki bu girdaptan kurtulmanın yolları olsa gerek. Bu sorunu atlatmanın belki de en önemli yollarından beri işinde, gücünde ve fikrinde kurt gibi insanların tavsiyelerine başvurmakta fayda var. Genel olarak ne zaman işimle ya da bir konuyla alakalı dara düşsem, o kurt gibidir yolunu yordamını bilir diye dedeme sarılıveririm.

Rusçada ise böyle bir ifadenin varlığından söz edilmesi mümkün değildir. Rus halkının bilincinde oluşan 'kurt' kavramı ile alakalı negatif çağrışımlar kendini 'iki yüzlü kimse' anlamında kullanılan volk v oveç'yey şkure (çev.: koyun postunda kurt) deyiminde net bir şekilde ortaya koymaktadır. Kurt kelimesinin bu kültürel anlamının Rus (konuşma) dilinde kullanılmasına ilişkin örnekler şu şekildedir:

\begin{abstract}
В октябре 1937 года выступил на конференции Свердловского партактива с к ритикой Вышинского и потребовал создать специальную комиссию для расследования всей деятельности этого человека. Часть сидевших в зале замерла от ужаса, а многие закричали: «Долой!», «Вон с трибуны!», «Волк во вечьей шкуре!» Сольц продолжал говорить. Несколько человек побежали к старику и стащили его с трибуны. Трудно сказать, почему Сталин не разделался с Сольцем попросту, то есть не арестовал его. (Çevr.: 1937 yllının ekim ayında gerçekleşen Sverdlovskiy parti aktivistleri konferansında Vyshinskiy eleştirilerek yaptığı tüm faaliyetlerin geniş çaplı araştırılması için özel bir komisyon kurulması talep edildi. Salonun içinde oturanların bir kısmının bu karardan dolayı donup kalırken, katılımcıların çoğu ise «Kahrolsun!», «Tribünden defol!», «İki yüzlü adam!» diye bağırdılar. Birkaç kişi yaşlı adamı tribünden indirmek için koştular. Stalinin neden Sol'tsem ile işini bitirmediğini yani onu yakalamadığını söylemek zor).

И хотя, выступая недавно в конгрессе, Обама пообещал, что реформа системы здравоохранения не приведет к росту бюджетного дефицита, демонстранты утверждают, что инициатива президента обернется для Америки экономическим крахом. На охват населения медицинской страховкой требует ассигновать из бюджета 600 млря долларов. По словам организаторов «чаепитий», это означает, что «Америка семимильными шагами движется к социализму». «Предатель американских идеалов», «красный дьявол», «волк в овечьей шкуре» - именовали президента противники, собравшиеся в Вашингтоне. (Çevr.: Geçenlerde bir kongrede Obama'nın sağlık konusundaki reformların bütçe açığını büyütmeyeceğini belirtmesine rağmen, göstericiler cumhurbaşkanın insiyatifi Amerikayı ekonomide çöküşe götüreceğini iddia ettiler. Halkın sağlık sigortasının yapılandırılması için 600 milyar doları bütçeden çıkarmak gerekiyordu. 'Çay partisi' organizatörlerine göre Amerika'nın hızlı adımlarla sosyalizme doğru ilerlemektedir. Washington'da toplanan göstericiler cumhurbaşkanını 'Amerika ideallerinin haini', 'Kırmızı şeytan', ‘'̇ki yüzlü adam' diye bağırarak adlandırdılar).
\end{abstract}

Sonuç olarak, 'kurt' sözcüğü asıl anlamından soyutlanarak kişinin bilincinde kültürel ya da sembolik anlamlar taşıdığı görülmektedir. Edinmiş olduğu bu kültürel anlamıyla 'kurt' sözcüğü Rus ve Türk dili zoomorf kod kültürü olma özelliği taşıdığı düşünülmektedir. 


\section{Sonuç}

Günümüz dilbilimin çalışmalarında antropolojik paradigma yaklaşımının etkisi dil ve kültür etkileşimł sorunlarının yeniden incelenmesini gündeme getirmiştir. Bu köklü değişim, dilbilimini diğer sosyal bilim dalları ile ortak çalışma alanlarında buluşturarak dilbiliminin hem sistemleşmesini hem de gelişimini sağlamıştır.

Dilbilimin genişlemesi ve gelişmesi çeşitli alt disiplinlerin doğuşunu tetiklemiştir. Çünkü, dil ve kültür etkileşim sorunlarının çözümü için dilbilim uzmanlarınca kullanılan yöntem ve metotlar istenilen sonuçları vermemekteydi. Rus dilbilim ekolünün gerçekleştirmiş olduğu kültürdilbilimsel çalışmalar sayesinde dil ve kültür sorunlarının çözümü için yeni alt disiplinler gün yüzüne çıkmaya başladı. Sonuç olarak, dil ve kültür etkileşimi sorunlarını ayrıntılı bir şekilde inceleyen, disiplinlerarası bağımsız bir bilim dalı olan kültürdilbilimin doğuşu gerçekleşmiş oldu.

V.N. Teliya ekolüne göre, kültürdilbilimi diğer disiplinlerden ayıran en önemli özellik, bu alanın dil ve kültür etkileşimi sorunlarını yaşayan (canlı) dil öbeklerinde araştırmasıdır. Buna bağlı olarak, V.N. Teliya ekolü uzmanları dil işaretlerinde somutlaşan kültür olgularının çıkarımını ve betimlenmesini deyimler odaklı yürütülen çalışmalarla yaptıkları görülmüştür. Bu okulun uzmanları, kültürdilbilimsel yaklaşım çerçevesinde dilde meydana gelen değişimlerin detaylı ve çok yönlü olarak ele alınması gerektiğini savunmaktadırlar. Diğer bir deyişle, köklü ve sağlam çözümler elde edilebilmesi için dil fenomeninin diğer farklı kuramlarla ilişkilendirilerek incelenmesi gerektiği üzerinde durulmaktadır. Çünkü, dil; iletişim aracı olmasından daha ziyade tarihsel, sosyal ve kültürel süreçleri iç bünyesinde yansıtan, kaydeden ve sonraki nesillere taşıyabilen bir unsur olarak ortaya çıkmaktadır.

Teliya ekolüne göre, dil göstergelerinde kaydedilen kültür olgularının ortaya çlkarımı ve tasviri ancak dil öbeklerinde (özellikle deyimlerde) uygulanacak kültürdilbilimsel analiz yöntemiyle mümkün olabileceği düşünülmektedir. Bu akımın benimsenmesi ile birlikte dilbilimciler söz ve söz gruplarında, deyimlerde, atasözlerinde, vecizelerde, özlü sözlerde ve kültür olgusu taşıyan tüm dil birimlerinde kültürdilbilimsel yaklaşımın sağlamış olduğu derin ve titiz analiz yöntemini kullanarak kod kültürlerini açı̆̆a çlkarmakta ve tasvir etmektedirler.

$\mathrm{Bu}$ çalışmada yer verilen örneklerde görüldüğü üzere, herhangi bir nesne asıl (birincil) anlamından uzaklaşarak herhangi bir toplumun dil dünya görüşünü ve mantalitesini yansitan çeşitli mecazi anlamlara gelmektedir. Stereotipler, semboller, mitler, arketipler, inançlar, adetler, gelenek görenekler gibi çeşitli kültürel anlamları dil işaretlerinde yansıtan, kaydeden ve koruyan ad ve ad takımlarına 'kod kültürleri’ denilmektedir.

Kod kültürleri, kültür anlamları dil ve kültür işaretlerine yansıtmakla kalmayıp aynı zamanda uzun yıllar boyunca bünyesinde muhafaza edebilme özelliğine sahiptir. Ayrıca, kod kültürleri bir milletin kültür kapısını aralayan dil olguları olduğu söylenebilir. V.N. Teliya ekolünün kültürdilbilimsel yaklaşım çerçevesinde bilim dünyasına kazandırmış olduğu kod kültürleri konulu çalışmalar, günümüzde başta Rusya Bilim Akademisi Dilbilim Enstitüsü ve M.V. Lomonosov Moskova Devlet Üniversitesinde olmak üzere çeşitli eğitim kurumlarının bünyesinde aktif bir şekilde yürütülmektedir.

Bu çalışmada V.N. Teliya ekolünün yaklaşımlarıyla kültürdilbilim alanın en önemli terimlerinden biri olan kod kültürleri incelenmiş olup ülkemiz sosyal bilim alanlarında tanınması amaçlanmıştır. Bu nedenle ortaya konulan terim ve terimlerin Türkçe karşıllğı öneri niteliğinde olup tartışmaya açıktır. 


\section{Kaynakça}

Arman, A. (2014). Balkan Naci İslimiyeli'nin 'Köşe yazarı' kıyafetini giydim: http://www.hurriyet.com.tr/balkan-naci-islimyelinin-kose-yazari-kiyafetini-giydim-27179363 [10.09.2019].

Bircan, U. (2015). "Saussure'de Dil, Dilbilim ve Göstergebilim". Sosyal Bilimler Araştırma Dergisi, 25: 43-66.

Doğan, Mehmet (2011). Büyük Türkçe Sözlük (23. Baskı). Ankara: Yazar.

Gudkov, D.B. (2004). "Yedinitsy Kodov Kul'turı: Problema Semiotiki". Yazık, Soznaniye, Kommunikatsiya, 26: 39-50.

Humboldt, F. W. (2000). Izbrannıye Trudı po Yazıkaznanıyu. Moskva: Progress.

Kovşova, M.L. (2012). Lingvokul'turologiçeskiy Metod vo Frazeologii: Kod Kul'turı. Moskva: Knijnıy Dom «Librokom», URSS.

Kozan, O. (ed.) (2014). Kültürdilbilim Temel Kavramlar ve Sorunlar. Ankara: Gazi kitabevi.

Krasnıh, V.V. (2002). Etnopsikholingvistika i Lingvokul'turologiya. Moskva: Gnozis.

Krasnıh, V.V. (2003). «Svoy» Sredi «Çujıh»: Mif ili Real'nost'?. Moskva: Gnozis.

Kuru, B. (2014). Ahilik Kültürü Haftası Denizli'de Renkli Etkinliklerle Kutlandı: http://www.denizlihaber.com/denizli/kent-genel/ahilik-haftasi-kutlandi/ [18.09.2019].

Levent, S. (2014). Sahne 'yurtıcı fikirler'in: http://www.hurriyet.com.tr/sahne-yirtici-fikirler-in27530712 [18.08.2019].

Maslova, V.A. (2001). Lİngvokul'turologiya: Uçebnoye Posobiye Dilya Studentov Vışşıh

Uçebnıh Zavedeniy. Moskva: İzdatel'skiy centr «Akademiya».

Ozhegov, S., Shvedova, N. (2006). Tolkovıy Slovar' Ruskkogo Yazıka: 80 ooo Slov i Frazeologiçeskih Yedinits. Moskva: OOO «A TEMP».

Rusça Ulusal Derlemi: http://www.ruscorpora.ru/new/ [19.07.2019].

Sapir, E. (1993). Izbrannıye Trudı po Yazykoznanıyu i Kul'turologii. Moskva: Progress.

Stepanov, Yu.S. (2004). Konstantı. Slovar' Russkoy Kul'turı. Moskva: Akademiçeskiy Proekt.

Teliya, V.N. (1996). Russkaya Frazeologiya: Semantiçeskiy, Pragmatiçeskiy i Lingvokul'turologiçeskiy Aspektı. Moskva: Yazıki Russkoy Kul'turı.

Teliya, V.N. (2006a). "Predisloviye”. Bol'shoy Frazeologiçeskiy Slovar' Russkogo Yazıka. Znaçenıye. Upotrebleniye. Kul'turologiçeskiy Kommentarı / V.N. Teliya (ed.). A.P. KNIGA, 6-14.

Teliya, V.N. (2006b). "Poslesloviye. Zamısel, tseli i zadaci frazeologiceskogo slovarya nogovo tipa". Bol'shoy Frazeologiçeskiy Slovar' Russkogo Yazıka. Znaçenıye / V.N. Teliya (ed.). A.P. KNİGA, 776-778.

Türk Dil Kurumu: https://tdk.gov.tr/ [10.09.2019]. 